\title{
Escuelas de flamenco y diversidad funcional: una mirada desde la inclusión en la ciudad de Granada
}

\author{
Flamenco schools and functional diversity: a view from inclusion in Granada
}

\author{
Carmen Ramírez-Hurtado \\ cramih@ugr.es \\ Departamento de Didáctica de la Expresión Musical, Plástica y Corporal \\ Universidad de Granada \\ Granada, España \\ ORCID: http://orcid.org/0000-0003-4744-3442
}

\author{
Consuelo Pérez-Colodrero \\ consuelopc@ugr.es \\ Departamento de Historia y Ciencias de la Música \\ Universidad de Granada \\ Granada, España \\ ORCID: http://orcid.org/0000-0001-9995-0417
}

doi: 10.7203/LEEME.45.16928

Recibido: 28-03-2020 Aceptado: 28-04-2020. Contacto y correspondencia: Consuelo Pérez-Colodrero, Departamento de Historia y Ciencias de la Música, Universidad de Granada, Antiguo Observatorio de Cartuja, s/n, 18071. Granada. España.

\section{Resumen}

Este trabajo tiene por finalidad estudiar los procesos de enseñanza-aprendizaje del baile flamenco en el contexto no formal de las escuelas de flamenco de Granada. Así, sus objetivos son averiguarsi a ellas acuden personas con diversidad funcional y determinar el enfoque pedagógico que estos centros asumen respecto a la misma, en cualquiera de sus tipologías (física, sensorial, intelectual y psíquica). Al efecto, se ha diseñado una investigación de corte cualitativo en tres fases que ha permitido (1) la identificación y caracterización de la totalidad de las escuelas de flamenco de la ciudad indicada, (2) la realización de entrevistas semidirigidas a 13 de sus directoras y profesoras y (3) la elaboración de historias de vida de 5 estudiantes con diversidad funcional (intelectual, física y sensorial) que acuden a tales centros. Los resultados sugieren que el profesorado adolece de falta de formación sobre la adaptación de sus enseñanzas para incluir a las personas con discapacidad, pese a que existe una gran empatía hacia este tipo de discentes. Así, se suelen practicar adaptaciones de manera intuitiva que llevan a que el flamenco se erija en un número importante de casos como una práctica inclusiva.

Palabras clave: Flamenco, discapacidad, educación no-formal.

\section{Abstract}

This work aims to study the teaching-learning processes of flamenco dance in the non-formal context of the flamenco schools of Granada. Thus, its objectives are to find out if they attract people with functional diversity and to determine the pedagogical approach that these centers take with respect to such diversity in any of its typologies (physical, sensory, intellectual, and psychic). To this end, a qualitative research in three phases has been designed that has allowed (1) the identification and characterization of all of the flamenco schools in the indicated city, (2) the conduct of semi-directed interviews with 13 of their directors and teachers, and (3) the elaboration of life stories of five students with functional diversity (intellectual, physical, and sensorial) who come to such centers. The results suggest that teachers suffer from a lack of training in adapting their teaching to include people with disabilities, despite the fact that there is great empathy towards this type of student. Thus, adaptations are often practiced intuitively, leading flamenco to become an inclusive practice in a significant number of cases.

Keywords: Flamenco, disability, non-formal education

@ Carmen Ramírez-Hurtado y Consuelo Pérez-Colodrero. The content of this article is the sole responsibility of the authors. The Revista Electrónica de LEEME and Universitat de València are not liable for any legal actions that may arise involving the article's content. Revista Electrónica de LEEME - Lista Electrónica Europea de Música en la Educación-. http://ojs.uv.es/index/php/LEEME/index ISSN: 1575-9563. Editores: Universidad de Valencia y Jesús Tejada. Visibilidad de esta revista: SCOPUS, Emerging Sources Citation Index (Clarivate), EBSCO, CINDOC (CSIC), Citefactor, COPAC, Dialnet, DICE (CSIC), DOAJ, e-revistas (CSIC), EBSCO Premier, ERIH+, Gale Cengage Learning, IN-RECS, IRESIE, LATINDEX, MIAR, OCLC Worldcat, RESH, REDIB, RILM Core Journals, SUDOC, ULRICHS. Esta revista es de acceso libre mediante licencia Creative Commons 4.0 CC by. Política de archivado: etiqueta verde SHERPA-ROMEO. 


\section{Introducción ${ }^{1}$}

El flamenco es una creación cultural acrisolada, fuertemente vinculada a la cultura popular andaluza (Berlanga-Fernández, 2009), un género híbrido que cristaliza en entornos variopintos, públicos y privados, familiares y profesionales. Así, tras atravesar un oscuro periodo durante el Regeneracionismo de finales del siglo XIX, el flamenco es redescubierto por Gerardo Diego, Fernando Villalón, Rafael Alberti o Federico García Lorca, todos ellos integrantes de la Generación de 1927, y dignificado por el Neojondismo de 1960, alcanzando el punto máximo de su reconocimiento institucional cuando, en 2007, el Estatuto de Andalucía lo reconoce como "elemento singular del patrimonio andaluz" (Jefatura del Estado, 2007, p.11885), propugnando su conservación y puesta en valor dentro de las políticas públicas de la región. El respaldo internacional a este legado llegó en 2010, cuando la UNESCO (2010) lo inscribía en su Lista Representativa del Patrimonio Cultural Inmaterial de la Humanidad (5.COM 6.39), que le otorga una fortaleza creciente como arte escénico.

Pese a lo expuesto, la literatura científica en torno al flamenco no es especialmente abundante. Destacan, en todo caso, trabajos que se interesan por este patrimonio a través de los factores que desencadenan su práctica (De Sancha-Navarro, Martos y Oliver-Alfonso, 2019) o analizan su presencia en el currículum de las aulas bajo un prisma cultural (Rodríguez-Quiles, 2006). A los efectos que interesan a este trabajo, una línea de trabajo particularmente interesante es la que estudia su metodología de enseñanza (Heras-Fernández, Espada y Cuellar-Moreno, 2019), que, no obstante, apenas encuentra continuidad a la hora de explicar su presencia en la educación obligatoria - ya sea Infantil, Primaria, Secundaria o Bachillerato (Padial-Ruz, Ibáñez-Granados, Hervás y Ubago-Jiménez, 2019; García-Gil y Azcune, 2012; NavasFernández y López-Martínez, 2018) - y en las Enseñanzas Artísticas (Romero, ChinchillaMinguet y Castillo-Rodríguez, 2020; Torres, Ortega-Ruz y Hidalgo, 2017). De estos estudios se desprende, que la mayoría de las personas que aprenden flamenco lo hacen en un contexto educativo no formal, es decir, en escuelas de flamenco (en adelante, EE.FF.) (Casas-Mas, Pozo y Montero, 2015). Son, por tanto, este tipo de centros los que facilitan el acceso de la mayoría de la población a este rico patrimonio, constituyéndose entonces como un sólido eslabón en su difusión y transmisión.

Una de las ciudades que, tradicionalmente, ha realizado una aportación sustancial al arte flamenco, en sus tres vertientes — cante, toque y baile-, es Granada. En efecto, desde el trabajo pionero de Molina-Fajardo (1974), hasta la descripción sistemática de Lorente-Rivas (1999), pasando por la aproximación de Arrebola (2018), numerosas propuestas, de diferente calibre y bajo distintos enfoques, abordan este particular, mostrando cómo la capital nazarí ha trazado su

\footnotetext{
1 Puesto que la inmensa mayoría de quienes protagonizan este trabajo son mujeres — directoras, profesoras, alumnas-, este texto utiliza el femenino como genérico.
}

@Carmen Ramírez-Hurtado y Consuelo Pérez-Colodrero. The content of this article is the sole responsibility of the authors. The Revista Electrónica de LEEME and Universitat de València are not liable for any legal actions that may arise involving the article's content. Revista Electrónica de LEEME - Lista Electrónica Europea de Música en la Educación-. http://ojs.uv.es/index/php/LEEME/index ISSN: 1575-9563. Editores: Universidad de Valencia y Jesús Tejada. Visibilidad de esta revista: SCOPUS, Emerging Sources Citation Index (Clarivate), EBSCO, CINDOC (CSIC), Citefactor, COPAC, Dialnet, DICE (CSIC), DOAJ, e-revistas (CSIC), EBSCO Premier, ERIH+, Gale Cengage Learning, IN-RECS, IRESIE, LATINDEX, MIAR, OCLC Worldcat, RESH, REDIB, RILM Core Journals, SUDOC, ULRICHS. Esta revista es de acceso libre mediante licencia Creative Commons 4.0 CC by. Política de archivado: etiqueta verde SHERPA-ROMEO. 
particular vínculo con este valioso legado a través de otras expresiones patrimoniales que típicamente se le arrogan. Entre estas, cabe destacar su pasado árabe, que cristaliza, por ejemplo, en las zambras que aún se organizan en el Sacromonte (López-López, 2015), pero también en la celebración del Concurso de Cante Jondo de 1922, que tuvo lugar en el Patio de los Aljibes de la Alhambra y supuso no sólo el primer certamen nacional de cante, sino un punto de partida para aclarar las relaciones entre este arte y figuras de amplio calado radicadas en Granada, como Manuel de Falla, Federico García Lorca y aún Isaac Albéniz (GiménezMiranda, 2010).

Siendo este patrimonio inclusivo desde sus orígenes - por haber surgido vinculado a clases marginadas, perseguidas o despreciadas, como la minoría gitano-andaluza (Steingress, 2005) —, cabría preguntarse sobre la accesibilidad de este patrimonio cultural, que, tanto por sus cualidades innatas como por estar reconocido como un bien universal, debiera ser universalmente accesible. Surgen, así, las siguientes preguntas de investigación, que guían el presente trabajo: las personas con diversidad funcional que residen en Granada y que así lo desean, ¿acceden al aprendizaje y la práctica del flamenco? Si es así, ¿cuántas son? ¿Qué problemática presentan y qué adaptaciones se realizan en las aulas a las que acuden para que esta manifestación artística pueda ser, efectivamente, inclusiva?

\section{Diversidad funcional, flamenco e inclusión: coordenadas básicas}

A la hora de definir la discapacidad, además de tener en cuenta aspectos relacionados con la biología, la medicina o la patología, es preciso considerar una serie de componentes construidos culturalmente. En este sentido, debe distinguirse entre deficiencia [impairment] y discapacidad [disability], que designan, respectivamente, la condición biológica y médica que origina la discapacidad y el significado que cada cultura o sociedad otorga a dicha condición (Ferreira, 2008). Así, si bien desde el punto de vista médico o biológico se diferencian cinco tipos de deficiencias - física, orgánica, sensorial, intelectual y psíquica (Organización Mundial de la Salud, 2001)—, socialmente se ha llegado a desactivar la primitiva conexión entre diversidad funcional y déficit.

Esto ha sido posible como resultado de los avances de los llamados Disability Studies que han configurado nuevos paradigmas de la discapacidad desde mediados del siglo XX (Tabla 1). En efecto, hasta la aparición del llamado paradigma social a finales de la década de 1960, los modelos de atención a la diversidad funcional o bien la habían considerado una anormalidad que obligaba al ostracismo social de las personas con discapacidad — paradigma tradicional — o bien una enfermedad que requería de sanación para que la persona afectada pudiera normalizarse e integrarse en el grupo - paradigma médico-. Estas visiones se superan con la propuesta que, resumida en palabras de Palacios y Romañach (2006), se formula sobre el precepto de que "todas las personas vean respetada su dignidad y sean aceptadas con sus

@Carmen Ramírez-Hurtado y Consuelo Pérez-Colodrero. The content of this article is the sole responsibility of the authors. The Revista Electrónica de LEEME and Universitat de València are not liable for any legal actions that may arise involving the article's content. Revista Electrónica de LEEME - Lista Electrónica Europea de Música en la Educación-. http://ojs.uv.es/index/php/LEEME/index ISSN: 1575-9563. Editores: Universidad de Valencia y Jesús Tejada. Visibilidad de esta revista: SCOPUS, Emerging Sources Citation Index (Clarivate), EBSCO, CINDOC (CSIC), Citefactor, COPAC, Dialnet, DICE (CSIC), DOAJ, e-revistas (CSIC), EBSCO Premier, ERIH+, Gale Cengage Learning, IN-RECS, IRESIE, LATINDEX, MIAR, OCLC Worldcat, RESH, REDIB, RILM Core Journals, SUDOC, ULRICHS. Esta revista es de acceso libre mediante licencia Creative Commons 4.0 CC by. Política de archivado: etiqueta verde SHERPA-ROMEO. 
diferencias por el simple hecho de ser humanas" (p.795) y no por sus posibilidades para curarse de su problemática o capacitarse. Por tanto, la inclusión efectiva se relaciona únicamente con los dos últimos paradigmas — social y de diversidad funcional — y supone, en palabras de Brabazon (2015), alcanzar "derechos, [tener capacidad de] elegir e independencia" (p.72).

Tabla 1. Paradigmas de la discapacidad

\begin{tabular}{|c|c|c|c|c|c|c|}
\hline PARADIGMA & MODELO & INCIDENCIA & CAUSA & ACTUACIÓN & OBJETIVO & $\begin{array}{c}\text { MODELO } \\
\text { DE } \\
\text { ESCUELA }\end{array}$ \\
\hline TRADICIONAL & $\begin{array}{c}\text { De } \\
\text { prescindencia }\end{array}$ & Hasta 1920 & $\begin{array}{l}\text { Anormalidad, } \\
\text { castigo divino }\end{array}$ & Marginalización & Segregación & $\begin{array}{l}\text { Excluyente } \\
\text { /Segregada }\end{array}$ \\
\hline $\begin{array}{l}\text { MÉDICO- } \\
\text { BIOLÓGICO }\end{array}$ & Habilitador & $1920-1970$ & Enfermedad & Reparación & Integración & $\begin{array}{l}\text { Segregada } \\
\text { /Integrada }\end{array}$ \\
\hline SOCIAL & $\begin{array}{c}\text { De autonomía } \\
\text { personal }\end{array}$ & 1970-2006 & $\begin{array}{c}\text { Sociedad } \\
\text { discapacitante, } \\
\text { excluyente y } \\
\text { discriminatoria }\end{array}$ & $\begin{array}{l}\text { Capacitación a } \\
\text { través de las } \\
\text { relaciones con el } \\
\text { entorno }\end{array}$ & Inclusión & $\begin{array}{l}\text { Integrada } \\
\text { /Inclusiva }\end{array}$ \\
\hline $\begin{array}{l}\text { DIVERSIDAD } \\
\text { FUNCIONAL }\end{array}$ & $\begin{array}{l}\text { Dignidad } \\
\text { humana }\end{array}$ & 2006- & $\begin{array}{l}\text { Diversidad de } \\
\text { funcionamientos }\end{array}$ & $\begin{array}{l}\text { Ampliación del } \\
\text { "conjunto- } \\
\text { capacidad" }\end{array}$ & Inclusión & Inclusiva \\
\hline
\end{tabular}

Fuente: elaboración propia a partir de Ainscow (2001), Armstrong, Armstrong y Spandagou (2011), Marchesi et al. (2002), Palacios (2008) y Toboso-Martín (2018)

Uno de los núcleos temáticos más recurrentes en los Disability Studies es la construcción de la identidad en el contexto de la diversidad funcional, atendiendo al papel que juega en la multiplicidad de identidades de cada persona (Sen, 1999) y a cómo se configura en torno a la personalidad y los roles sociales. Así, la literatura científica (Johnstone, 2004; Darling, 2014) aporta un amplio abanico de posibles orientaciones, articuladas fundamentalmente sobre la autopercepcion y la relación con el entorno. Para los propósitos de esta investigación, podemos resumirlas en (1) negación — rechazo individual de la propia condición-, (2) aceptación — vivencia de normalización positiva - y (3) activismo orientación hacia la lucha social, alzándose la discapacidad como la principal de las identidades-. Estas opciones no son excluyentes entre sí, no sólo porque la identidad es siempre un proceso, sino porque "la discapacidad es un estado fluido" (Barnartt, 2010, p.1) del que es posible entrar y salir en un determinado momento.

Otro aspecto central en los Disability Studies es su implicación en la educación, con un enfoque crítico hacia las tradiciones, estructuras y culturas educativas que resultan discriminatorias para estas personas. En este sentido, se reconocen, de manera paralela a los paradigmas de la discapacidad, cuatro tipos de escuelas, según las políticas educativas opten por la exclusión, segregación, integración o inclusión de las personas con diversidad funcional (Iyanga, 2017; Tabla 1). La implantación en las aulas de los sucesivos paradigmas de la discapacidad ha sobrevenido con el lógico retraso que implica la elaboracion de las

@Carmen Ramírez-Hurtado y Consuelo Pérez-Colodrero. The content of this article is the sole responsibility of the authors. The Revista Electrónica de LEEME and Universitat de València are not liable for any legal actions that may arise involving the article's content. Revista Electrónica de LEEME - Lista Electrónica Europea de Música en la Educación-. http://ojs.uv.es/index/php/LEEME/index ISSN: 1575-9563. Editores: Universidad de Valencia y Jesús Tejada. Visibilidad de esta revista: SCOPUS, Emerging Sources Citation Index (Clarivate), EBSCO, CINDOC (CSIC), Citefactor, COPAC, Dialnet, DICE (CSIC), DOAJ, e-revistas (CSIC), EBSCO Premier, ERIH+, Gale Cengage Learning, IN-RECS, IRESIE, LATINDEX, MIAR, OCLC Worldcat, RESH, REDIB, RILM Core Journals, SUDOC, ULRICHS. Esta revista es de acceso libre mediante licencia Creative Commons 4.0 CC by. Política de archivado: etiqueta verde SHERPA-ROMEO. 
legislaciones pertinentes. Así, en el caso de España, la legislación sobre educación inclusiva no comienza hasta 1985, con Real Decreto 334/1985, de 6 de marzo, de ordenación de la Educación Especial (Ministerio de Educación y Ciencia, 1985). Por otra parte, y dentro de este marco educativo, la literatura científica suele coincidir en el valor de las artes, en general, para propiciar la verdadera inclusión (Kallio-Tavin, 2020), ocupando la música un lugar importante entre estas, según han mostrado Levy, Robb y Jindal-Snape (2017), Calderón-Almendros y Calderón-Almendros (2016) o Solvang (2018). En este sentido, es importante que las relaciones entre música y diversidad funcional no tengan como marco de referencia ni la Musicoterapia ni la Educación Especial, pues debe reconocerse "el derecho de las personas con alguna deficiencia a ser incluidas en la praxis musical general y a escoger qué instrumento tocar o qué disciplina practicar sobre la base de sus inclinaciones personales y no sobre la deficiencia física" (Sunandan, 2019, p.779).

\section{Objetivos y metodología}

El objetivo general del trabajo es estudiar cómo acceden al flamenco las personas con diversidad funcional, tomando como estudio de caso la ciudad de Granada. A la hora de concretarlo, los objetivos específicos para la investigación se concretan en:

1. Determinar el número de EE.FF. que hay en la ciudad y sus características principales - localización, datos de contacto, enseñanzas que imparten, horario, equipo docente, honorarios, presencia en redes sociales-.

2. Averiguar si hay alumnas con diversidad funcional $-\mathrm{y}$ de qué tipo- en estas EE.FF.

3. Identificar el enfoque pedagógico que estas EE.FF. asumen respecto a la diversidad funcional, indagando sobre las posibles actuaciones para su atención y adaptaciones metodológicas que despliegan para alcanzar una inclusión efectiva, es decir, para que existan las mismas posibilidades de acceso y disfrute del flamenco para las personas funcionalmente diversas, apoyando verdaderamente su aprendizaje y garantizando la equidad en la educación (UNESCO, 2017).

Para abordarlos, dada la complejidad y lo inexplorado del tema, se han utilizado dos enfoques metodológicos diferenciados pero interconectados coherentemente y secuenciados en tres fases. De este modo, el diseño de la investigación — que es explorativa y, por tanto, presenta numerosos elementos que aguardan futuros análisis — queda como sigue:

Fase I. Identificación y caracterización de las EE.FF. Inicialmente, se procede a un muestreo simple y sistemático, a través de internet, encaminado a confeccionar un listado exhaustivo de las EE.FF. presentes en Granada. Los datos de esta primera exploración, que se

@Carmen Ramírez-Hurtado y Consuelo Pérez-Colodrero. The content of this article is the sole responsibility of the authors. The Revista Electrónica de LEEME and Universitat de València are not liable for any legal actions that may arise involving the article's content. Revista Electrónica de LEEME - Lista Electrónica Europea de Música en la Educación-. http://ojs.uv.es/index/php/LEEME/index ISSN: 1575-9563. Editores: Universidad de Valencia y Jesús Tejada. Visibilidad de esta revista: SCOPUS, Emerging Sources Citation Index (Clarivate), EBSCO, CINDOC (CSIC), Citefactor, COPAC, Dialnet, DICE (CSIC), DOAJ, e-revistas (CSIC), EBSCO Premier, ERIH+, Gale Cengage Learning, IN-RECS, IRESIE, LATINDEX, MIAR, OCLC Worldcat, RESH, REDIB, RILM Core Journals, SUDOC, ULRICHS. Esta revista es de acceso libre mediante licencia Creative Commons 4.0 CC by. Política de archivado: etiqueta verde SHERPA-ROMEO. 


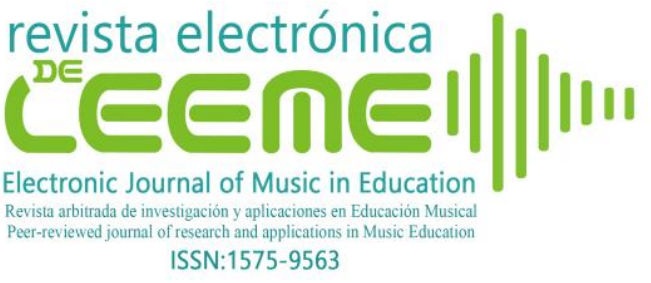

realizó a través de diferentes buscadores y redes sociales — Google, Bing, Facebook, Google+, Instagram, Twitter-, se completaron y triangularon con los obtenidos de las entrevistas de la Fase II, resultando entonces una búsqueda inductivo-deductiva. Finalmente, se integraron en una amplia matriz que, fundamentalmente, recogió informaciones relacionadas con su localización y contacto, la accesibilidad y características de su sitio web, el tipo de organización docente que se sigue o el número de alumnas que acuden a estos programas.

Fase II. Contacto con las EE.FF. A través de correo electrónico, llamadas telefónicas y mensajería instantánea - WhatsApp - , se concertaron visitas y/o entrevistas telefónicas con las responsables de las diferentes escuelas, concretándose así la muestra aceptante y productora de datos mediante muestreo causal, es decir, a partir de las directoras y escuelas que efectivamente respondieron a alguna de las tres vías de contacto indicadas.

Fase III. Estudio cualitativo. Aplicando un enfoque humanístico-interpretativo, se realizaron entrevistas semiestructuradas a las directoras de las EE.FF. Siguiendo a Ruiz (2003), se planificaron las preguntas - centradas fundamentalmente en diferentes aspectos de la escuela y de las personas con diversidad funcional que en ellas estudian flamenco (Anexo 1) mediante un guion secuenciado y orientado a satisfacer los objetivos de la investigación (Hoinville y Jowell, 1978). Para validar la entrevista, se elaboró una propuesta piloto, que fue evaluada por varias especialistas del área de Música y de Didáctica de la Expresión Musical con la finalidad de que las preguntas fueran plenamente comprensibles y pertinentes a la investigación (Cotán-Fernández, 2015)². Finalmente, las EE.FF. facilitaron los datos de contacto de algunas de sus estudiantes con diversidad funcional, lo que permitió obtener los permisos correspondientes para que estas fueran asimismo entrevistadas y elaborar historias de vida de personas con distintas capacidades, generando un marco interpretativo que pudiera revelar el sentido de sus existencias (Pérez-Serrano, 2002) en el contexto de la practica del flamenco. En este último caso, la muestra fue causal e intencional, pues se procuró que estuvieran representadas distintas discapacidades. Para garantizar el anonimato de las protagonistas de este trabajo, (1) se ha asignado una letra al azar para denominar las EE.FF.; (2) se ha atribuido un nombre anglosajón con la misma inicial que la letra de la escuela a las directoras y, de la misma manera, (3) se ha cambiado el nombre de las informantes por otros de origen sánscrito que asimismo comparten inicial con la escuela en la que estudian. La población resultante del proceso descrito para la Fase I es de 22 EE.FF. De este conjunto, 13 aceptaron participar en esta investigación y, por tanto, constituyen la muestra sobre la que se asienta el presente trabajo, practicandose, durante la Fase II, 13 entrevistas a sus correspondientes directoras y realizaron 5 historias/episodios de vida a partir de los testimonios de otras tantas estudiantes con diversidad funcional física, psíquica y sensorial. Sobre tales materiales, resumidos en la Tabla 2, se asienta este trabajo y versan los apartados que aparecen a continuación.

\footnotetext{
${ }^{2}$ Los especialistas consultados pertenecen a las universidades de Granada, Jaén, Complutense de Madrid y Valencia. Se añade a la directora de la EE.FF. M, que aporta al conjunto una visión profesional.
}

@Carmen Ramírez-Hurtado y Consuelo Pérez-Colodrero. The content of this article is the sole responsibility of the authors. The Revista Electrónica de LEEME and Universitat de València are not liable for any legal actions that may arise involving the article's content. Revista Electrónica de LEEME - Lista Electrónica Europea de Música en la Educación-. http://ojs.uv.es/index/php/LEEME/index ISSN: 1575-9563. Editores: Universidad de Valencia y Jesús Tejada. Visibilidad de esta revista: SCOPUS, Emerging Sources Citation Index (Clarivate), EBSCO, CINDOC (CSIC), Citefactor, COPAC, Dialnet, DICE (CSIC), DOAJ, e-revistas (CSIC), EBSCO Premier, ERIH+, Gale Cengage Learning, IN-RECS, IRESIE, LATINDEX, MIAR, OCLC Worldcat, RESH, REDIB, RILM Core Journals, SUDOC, ULRICHS. Esta revista es de acceso libre mediante licencia Creative Commons 4.0 CC by. Política de archivado: etiqueta verde SHERPA-ROMEO. 


\section{Resultados}

Podrían definirse las EE.FF. como el contexto de enseñanza-aprendizaje no formal donde se imparten las disciplinas relacionadas con este patrimonio cultural - baile, cante, toque - excluyéndose de esta categoría las enseñanzas oficiales, como el Conservatorio -que incluye estas enseñanzas, por ejemplo, en el caso de los conservatorios superiores de Murcia, Barcelona y Córdoba-, y los contextos de enseñanza-aprendizaje informal, es decir, los que se desarrollan a través de la red familiar o de amigos. Como consecuencia de lo indicado, en las EE.FF. no existe un currículum como tal y, por tanto, no es posible hablar de adaptación al uso, aunque tal circunstancia no sea impedimento para que se produzca una modificación metodológica y creativa a fin de que los programas sean accesibles al conjunto de alumnas que a ellos acuden.

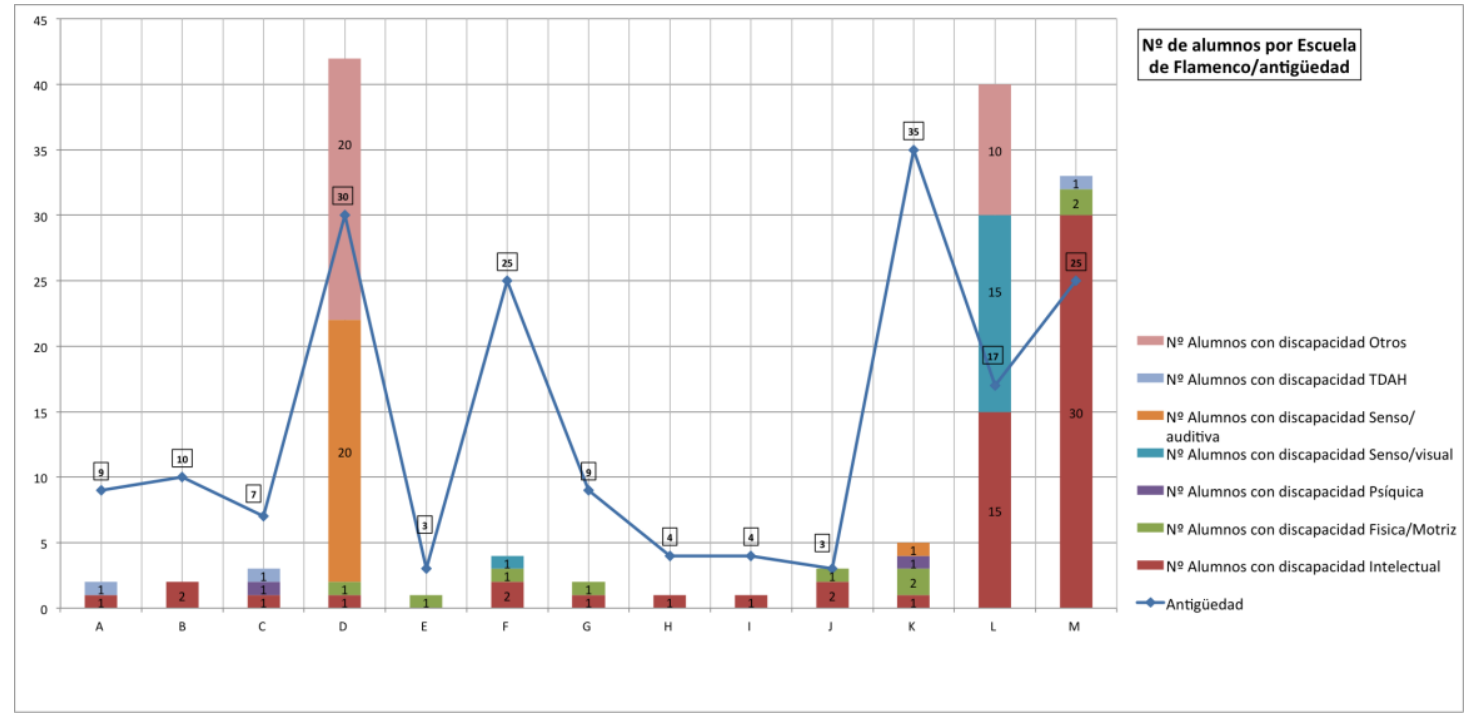

Figura 1. Antigüedad de las EE.FF. de Granada y relación con la presencia de alumnas con discapacidad. Fuente: elaboración propia

La investigación desplegada ha verificado la existencia de 22 EE.FF. en Granada. Salvo en los casos de las escuelas A, B e I, que ofrecen las diferentes vertientes del flamenco, las escuelas estudiadas solo ofrecen clases de baile. El número de alumnas que acogen es bastante homogéneo, pues ronda los 80-90 por escuela, y su localización apunta a que existe una por cada barrio o distrito.

Las 13 escuelas que participaron en la investigación han tenido, en algún momento de su trayectoria, estudiantes con diversidad funcional (Figura 1). El número total de estas estudiantes que se ofrece en este trabajo, no obstante, es bastante aproximado, pues tiene en cuenta el histórico de los centros. Las razones para esta manera de proceder tienen que ver con

@Carmen Ramírez-Hurtado y Consuelo Pérez-Colodrero. The content of this article is the sole responsibility of the authors. The Revista Electrónica de LEEME and Universitat de València are not liable for any legal actions that may arise involving the article's content. Revista Electrónica de LEEME - Lista Electrónica Europea de Música en la Educación-. http://ojs.uv.es/index/php/LEEME/index ISSN: 1575-9563. Editores: Universidad de Valencia y Jesús Tejada. Visibilidad de esta revista: SCOPUS, Emerging Sources Citation Index (Clarivate), EBSCO, CINDOC (CSIC), Citefactor, COPAC, Dialnet, DICE (CSIC), DOAJ, e-revistas (CSIC), EBSCO Premier, ERIH+, Gale Cengage Learning, IN-RECS, IRESIE, LATINDEX, MIAR, OCLC Worldcat, RESH, REDIB, RILM Core Journals, SUDOC, ULRICHS. Esta revista es de acceso libre mediante licencia Creative Commons 4.0 CC by. Política de archivado: etiqueta verde SHERPA-ROMEO. 
el enunciado de los objetivos de la investigación, pero también con que la identificación de ciertas deficiencias - las conocidas como "discapacidades invisibles" (Kattari, Olzman y Hanna, 2018) - es compleja: para empezar, porque su presencia en grupos grandes queda bastante diluida; también, porque en ocasiones las familias o las propias estudiantes ocultan las diferencias; finalmente, porque la diversidad funcional es una situación porosa, tal y como ya se ha indicado, lo que redunda en que haya problemáticas, como las derivadas de la edad Alzheimer o demencia senil, degeneraciones osteomusculares (Figura 1, "Otros")-, que no siempre son consideradas como tales por la sociedad, en general, o por las profesoras entrevistadas, en particular. Parece claro, en cualquier caso, que la antigüedad de las escuelas es la única variable que incide en el número de alumnas con discapacidad que ha recibido, pues a mayor número de años de funcionamiento del centro, mayor número de personas con distintas capacidades se contabiliza.

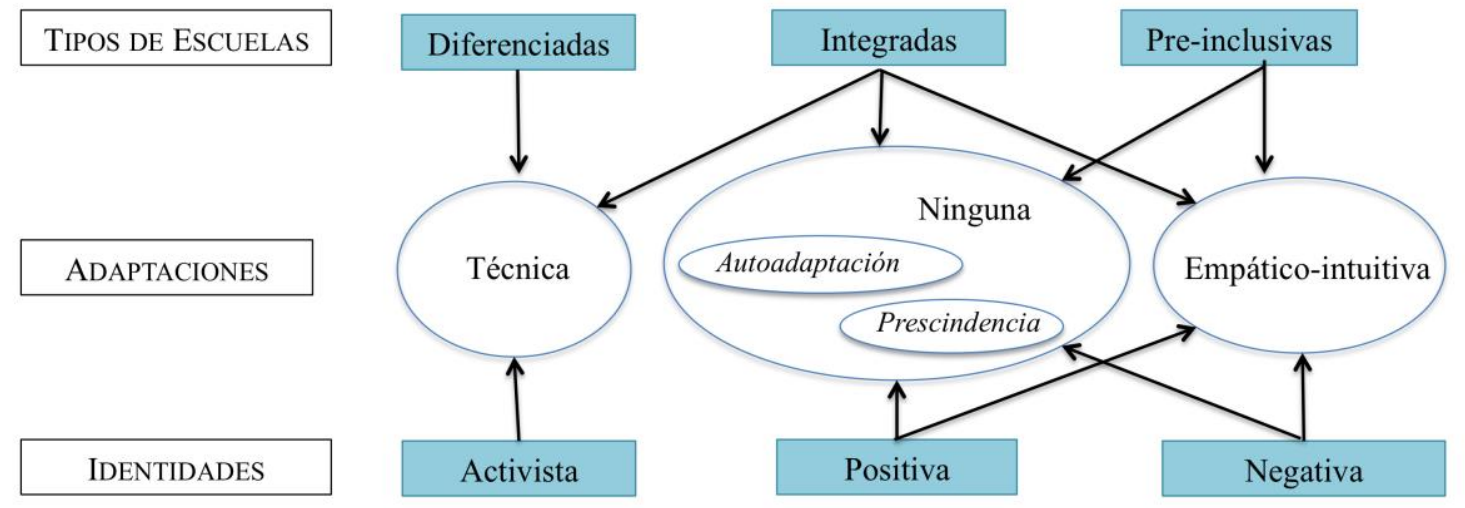

Figura 2. Núcleos temáticos de análisis de las EE.FF. y modos de inclusión de las personas con diferentes capacidades. Fuente: elaboración propia

El resto de elementos y datos recabados para la investigación se han organizado en una serie de núcleos temáticos de análisis que tienen que ver con los tipos de escuela encontrados, las adaptaciones metodológicas que se aplican en el caso de alumnas con diversidad funcional y las identidades de las personas entrevistadas (Figura 2). Para alcanzarlos, se aplicó un proceso inductivo-deductivo basado en la fenomenología interpretativa de tipo thick description (Jorgensen, 2009), que viene siendo habitual en la línea temática sobre la que se ocupa este trabajo —Disability Studies (Charalampos, Silva y Kudlacek, 2015; Davis, 2017), inclusión educativa (Olsson, Sand y Stenberg, 2019), música y discapacidad (Oakland, MacDonald y Flowers, 2014; Staab y Dvorak, 2019) e incluso aprendizaje de la danza inclusiva (Zitomer y Reid, 2011), por citar solo algunos ejemplos-.

Como consecuencia, ha sido posible diferenciar entre EE.FF. diferenciadas, integradas y pre-inclusivas (Tabla 2). Las primeras trabajan específicamente con alumnas con discapacidad y tienen una finalidad terapéutica. Entre estas, un caso paradigmático es el de L, cuya directora,

@Carmen Ramírez-Hurtado y Consuelo Pérez-Colodrero. The content of this article is the sole responsibility of the authors. The Revista Electrónica de LEEME and Universitat de València are not liable for any legal actions that may arise involving the article's content. Revista Electrónica de LEEME - Lista Electrónica Europea de Música en la Educación-. http://ojs.uv.es/index/php/LEEME/index ISSN: 1575-9563. Editores: Universidad de Valencia y Jesús Tejada. Visibilidad de esta revista: SCOPUS, Emerging Sources Citation Index (Clarivate), EBSCO, CINDOC (CSIC), Citefactor, COPAC, Dialnet, DICE (CSIC), DOAJ, e-revistas (CSIC), EBSCO Premier, ERIH+, Gale Cengage Learning, IN-RECS, IRESIE, LATINDEX, MIAR, OCLC Worldcat, RESH, REDIB, RILM Core Journals, SUDOC, ULRICHS. Esta revista es de acceso libre mediante licencia Creative Commons 4.0 CC by. Política de archivado: etiqueta verde SHERPA-ROMEO. 
bailaora profesional y licenciada en Psicología, entiende el flamenco como una fórmula de extender la psicobiografía de cada persona: "Yo hago meditación guiada por el movimiento, mindfulness con la danza, para que los pacientes puedan sacar su expresión natural. [...] No me planteo el flamenco como disciplina, sino como terapia, [como] desarrollo personal" (Leslie, entrevista, 20 de enero de 2020). Acaso por esta razón, la escuela se dedica casi en exclusiva a organizar talleres y cursos para diferentes asociaciones relacionadas con la discapacidad, como la ONCE, de manera que su labor entronca con el paradigma médico de la diversidad funcional.

Existen asimismo escuelas integradas, de las que un ejemplo prototípico es $\mathrm{M}$. Su directora posee formación universitaria y tiene experiencia en danza y teatro inclusivos, en la línea del psicoballet de Maite León (n. Madrid, 1968). Consecuentemente, trabaja con dos grupos específicos de personas con Síndrome de Down y, quizá por su especial sensibilidad inclusiva, algunas de sus estudiantes con diversidad funcional están en grupos estándar con actuaciones adaptativas de diversa índole, como Mitali. Destaca, no obstante, el caso de Meera por haber pasado a un nivel semi-profesional por su esfuerzo y aptitudes. Siendo, pues, una escuela integrada, $M$ presenta rasgos de escuela verdaderamente inclusiva, en tanto que las alumnas con diversidad funcional se benefician de las mismas actividades y procesos y asumen roles similares a las alumnas sin ella.

Una tercera categoría de las EE.FF. de Granada es la de las pre-inclusivas, denominación que responde a que, aunque se trata de centros en los que todas las personas participan de los mismos espacios y de las mismas actividades, sus fórmulas para la adaptación no provienen de una formación especifica del profesorado en temas de inclusión. En efecto, las escuelas acogen a estudiantes con diversidad funcional pero el trabajo para que la inclusión sea efectiva recae, casi en todos los casos, en las propias estudiantes, que no obstante se ven apoyadas por la actitud empática de muchas profesoras. Puede decirse entonces que la inclusión en estas EE.FF. se produce sin que existan unos recursos que decididamente la guíen. A esta categoría pertenece el grueso de las escuelas estudiadas.

Por lo que toca a las adaptaciones identificadas, un primer grupo son las de tipo técnico: aquellas que derivan de la formación específica del profesorado o bien de la presencia de personal de apoyo (Gerrity, Hourigan y Horton, 2013). Como tales, solo se encuentran en las EE.FF. diferenciadas o en las integradas, como D y L. Así, Daisy explica que contaba con intérpretes de lengua de signos cuando impartía clase a los grupos de la asociación de sordos, lo que le permitía dar las instrucciones con mayor claridad. Algo semejante ocurre con las adaptaciones que realizaba Leslie para trabajar con alumnas con ceguera. Su testimonio explica cabalmente la especificidad de las modificaciones practicadas:

"Ellas tocan la postura. Solo se puede hacer con grupos muy pequeños o con personas de apoyo, siempre one to one. [...] Yo me inspiro en el grupo de teatro para ciegos: se aprenden el escenario de memoria. Tienen que ensayar mucho y ponemos identificadores en el suelo, velcros, para que no se caigan fuera del escenario. [...] Al final, 'parece que ven'. Eso sí,

@Carmen Ramírez-Hurtado y Consuelo Pérez-Colodrero. The content of this article is the sole responsibility of the authors. The Revista Electrónica de LEEME and Universitat de València are not liable for any legal actions that may arise involving the article's content. Revista Electrónica de LEEME - Lista Electrónica Europea de Música en la Educación-. http://ojs.uv.es/index/php/LEEME/index ISSN: 1575-9563. Editores: Universidad de Valencia y Jesús Tejada. Visibilidad de esta revista: SCOPUS, Emerging Sources Citation Index (Clarivate), EBSCO, CINDOC (CSIC), Citefactor, COPAC, Dialnet, DICE (CSIC), DOAJ, e-revistas (CSIC), EBSCO Premier, ERIH+, Gale Cengage Learning, IN-RECS, IRESIE, LATINDEX, MIAR, OCLC Worldcat, RESH, REDIB, RILM Core Journals, SUDOC, ULRICHS. Esta revista es de acceso libre mediante licencia Creative Commons 4.0 CC by. Política de archivado: etiqueta verde SHERPA-ROMEO. 
trabajamos palos no muy complejos, como tangos, rumbas, sevillanas, bulerías; a veces solo una parte" (Leslie, entrevista, 20 de enero de 2020).

Tabla 2. Relación de escuelas de flamenco estudiadas

\begin{tabular}{|c|c|c|c|c|c|c|c|}
\hline & ESCUELA & DIRECTORA & TIPOLOGÍA & ADAPTACIONES & ALUMNAS & DISCAPACIDAD & IDENTIDAD $^{\mathrm{C}}$ \\
\hline 1 & $\mathrm{~A}$ & Austin & $\mathrm{pI}$ & & & & \\
\hline 2 & $\mathrm{~B}$ & Betty & pI & & Balvan & It & \\
\hline \multirow[t]{2}{*}{3} & $\mathrm{C}$ & Cindy & pI & Pc, EI, aA & Charu & $\mathrm{P}$ & N- \\
\hline & & & & & Chandra & It & $\mathrm{P}+$ \\
\hline \multirow[t]{2}{*}{4} & $\mathrm{D}$ & Daisy \& Dana & In & $\mathrm{T}, \mathrm{EI}, \mathrm{aA}$ & Denali $^{\mathrm{a}}$ & $\mathrm{Sa}$ & $\mathrm{P}+$ \\
\hline & & & & & Deepa $^{b}$ & $\mathrm{~F}$ & $\mathrm{P}+$ \\
\hline 5 & E & Edith & $\mathrm{pI}$ & EI & Eka & $\mathrm{F}$ & \\
\hline \multirow[t]{3}{*}{6} & $\mathrm{~F}$ & Farrah & pI & EI & Falguni & It & \\
\hline & & & & & Farida & $\mathrm{Sv}$ & \\
\hline & & & & & Faiza & $\mathrm{F}$ & \\
\hline \multirow[t]{2}{*}{7} & G & Gigi & $\mathrm{pI}$ & EI, aA & Gana & It & $\mathrm{P}+$ \\
\hline & & & & & Geet & $\mathrm{F}$ & N- \\
\hline 8 & $\mathrm{H}$ & Harper & $\mathrm{pI}$ & $\mathrm{aA}$ & Hanima & It & $\mathrm{P}+$ \\
\hline 9 & I & Izna & [pI] & & & & \\
\hline \multirow[t]{3}{*}{10} & $\mathrm{~J}$ & Janet & pI & EI & Jana & $\mathrm{F}$ & \\
\hline & & & & & Jenya & It & N- \\
\hline & & & & & Jai & It & \\
\hline \multirow[t]{6}{*}{11} & K & Karen & $\mathrm{pI}$ & Pc, aA, EI & Kaia & F & \\
\hline & & & & & Karisma & $\mathrm{F}$ & \\
\hline & & & & & Kaya & It & \\
\hline & & & & & Kabir & It & \\
\hline & & & & & Kamala & $\mathrm{P}$ & $\mathrm{P}+$ \\
\hline & & & & & Kinari & $\mathrm{Sa}$ & $\mathrm{P}+$ \\
\hline 12 & $\mathrm{~L}$ & Leslie & $\mathrm{D}$ & $\mathrm{T}$ & Lopa & $\mathrm{Sa}$ & Ac \\
\hline 13 & M & Maddie & I & T, EI, aA & Mitali & $\mathrm{F}$ & $\mathrm{P}+$ \\
\hline & & & & & Meera & It & \\
\hline $14^{\mathrm{d}}$ & $\mathrm{N}$ & $\begin{array}{l}\text { Nancy \& } \\
\text { Nola }\end{array}$ & $\mathrm{pI}$ & Pc, Aa & Nahali & $\mathrm{Sa}$ & $\mathrm{P}+$ \\
\hline
\end{tabular}

El segundo grupo de adaptaciones son de tipo empático-intuitivo y se caracterizan porque el profesorado involucrado las practica sin haber recibido formación pedagógica específica en materia de discapacidad y, por tanto, resultan de (a) la voluntad de dicho profesorado de incluir a sus estudiantes con diversidad funcional en la enseñanza del flamenco y de (b) su afinidad, sintonía y comprensión con este tipo de alumnas. Se pueden traer a colación

\footnotetext{
${ }^{3}$ Nota: D (Diferenciada); In (Integrada); pI (Pre-inclusiva); T (Técnica); aA (Auto-adaptación); Pc (Prescindencia); EI (Empático-intuitiva); F (Física); P (Psíquica); It (Intelectual); Sv (Senso-visual); Sa (Senso-auditiva); Ac (Activista); P+ (Positiva); N- (Negativa).

${ }^{a}$ Los nombres en cursiva se corresponden con alumnas que han sido entrevistadas.

${ }^{\mathrm{b}}$ Los nombres en negrita se corresponden con alumnas que han alcanzado nivel profesional o semi-profesional.

c Solo se indica en los casos en que se han realizado entrevistas personales o está ampliamente referida por las profesoras.

${ }^{\mathrm{d}}$ La escuela $\mathrm{N}$ no participó directamente en el trabajo, pero aparece a través del testimonio de Nahali, que fue alumna de dicha escuela y a la que se contactó, a su vez, a través de Karen, directora de la escuela K.
}

@ Carmen Ramírez-Hurtado y Consuelo Pérez-Colodrero. The content of this article is the sole responsibility of the authors. The Revista Electrónica de LEEME and Universitat de València are not liable for any legal actions that may arise involving the article's content. Revista Electrónica de LEEME - Lista Electrónica Europea de Música en la Educación-. http://ojs.uv.es/index/php/LEEME/index ISSN: 1575-9563. Editores: Universidad de Valencia y Jesús Tejada. Visibilidad de esta revista: SCOPUS, Emerging Sources Citation Index (Clarivate), EBSCO, CINDOC (CSIC), Citefactor, COPAC, Dialnet, DICE (CSIC), DOAJ, e-revistas (CSIC), EBSCO Premier, ERIH+, Gale Cengage Learning, IN-RECS, IRESIE, LATINDEX, MIAR, OCLC Worldcat, RESH, REDIB, RILM Core Journals, SUDOC, ULRICHS. Esta revista es de acceso libre mediante licencia Creative Commons 4.0 CC by. Política de archivado: etiqueta verde SHERPA-ROMEO. 
los casos de (1) Eka, una niña de unos nueve años con discapacidad física -parálisis cerebral-, sobre cuyas rodillas Edith marcaba el taconeo; (2) Denali, sorda, a quien su profesora Daisy, pese a las rotaciones que practica por lo numeroso del grupo al que pertenece, siempre ubica en primera fila, en el centro, para que pueda leerle los labios cuando da las instrucciones; (3) o Mitali, que tras siete operaciones articulares no puede permanecer más de quince minutos de pie o usar tacones, de manera que Maddie, su profesora, no solo le permite sentarse cada vez que lo necesite - ocasión que esta alumna aprovecha para grabar algunos pasos para luego repasarlos "en casa [...] en sesiones muy breves para no quedar[se] atrás"-, sino que la anima explicándole que "la Chucha, una de las mejores bailaoras de flamenco, no se ponía zapatos porque no tenía dinero para comprárselos" (Maddie, entrevista, 27 de enero de 2020).

Algunas de las profesoras entrevistadas manifiestan además la gran satisfacción que supone el trabajo con personas funcionalmente diversas, a las que encuentran muy agradecidas y cuyos resultados hacen que su esfuerzo compense. En este sentido, Betty, hablando de Balvan, un alumno con Síndrome de Down, expresa no solo que se trata de "uno más" en la clase, sino que "en la actuación fin de curso [se] bebía las lágrimas". Para ella, entonces, "el baile es una ayuda para integrarse con la gente", ya que "hay que saber sacar de cada uno lo que tiene", independientemente de si se trata de una persona con diversidad funcional o no (Betty, entrevista, 15 de enero de 2020).

En los casos en que las profesoras manifiestan no practicar ninguna adaptación, es posible descubrir dos realidades de fondo. La primera es un enfoque general de prescindencia - la discapacidad vista desde un paradigma tradicional, en las que hay un punto marginalizador- - Es el caso de las EE.FF. que buscan la profesionalización de sus alumnas y son cercanas a la educación formal. Así, Cindy explica que no siempre es posible que las personas con diversidad funcional aprendan el baile flamenco, dado que se trata de un arte "complejo, que requiere atención, buena forma física, concentración y memoria coreográfica" (Cindy, entrevista, 15 de enero de 2020). Dado que, además, "los movimientos son poco naturales", llega un momento en el que considera que "no puede hacer ninguna adaptación", porque "no todo el mundo puede seguir el ritmo" (íbid.). La segunda de las realidades que puede atisbarse es la auto-adaptación por parte de las alumnas o de sus familias. Un ejemplo revelador el de Nahali, a quien su problemática - sordera-lleva a dedicar mucho tiempo y esfuerzo a memorizar las coreografías: audiovisiona sus grabaciones con paradas y repeticiones constantes para aprender los pasos, las practica sin música y estudia aparte las pocas referencias musicales que puede apreciar. Sus resultados son tan eficaces que, para quien la ve, es imposible apreciar la diferencia. En el caso de las autoadaptaciones mediadas por la familia, es pertinente mencionar a Hanima, hija de músicos profesionales que han sabido establecer una muy positiva relación entre la niña y el arte sonoro, lo que ha resultado en que su diferente capacidad no sea obstáculo para desarrollar un llamativo talento para la danza y los instrumentos de percusión.

@Carmen Ramírez-Hurtado y Consuelo Pérez-Colodrero. The content of this article is the sole responsibility of the authors. The Revista Electrónica de LEEME and Universitat de València are not liable for any legal actions that may arise involving the article's content. Revista Electrónica de LEEME - Lista Electrónica Europea de Música en la Educación-. http://ojs.uv.es/index/php/LEEME/index ISSN: 1575-9563. Editores: Universidad de Valencia y Jesús Tejada. Visibilidad de esta revista: SCOPUS, Emerging Sources Citation Index (Clarivate), EBSCO, CINDOC (CSIC), Citefactor, COPAC, Dialnet, DICE (CSIC), DOAJ, e-revistas (CSIC), EBSCO Premier, ERIH+, Gale Cengage Learning, IN-RECS, IRESIE, LATINDEX, MIAR, OCLC Worldcat, RESH, REDIB, RILM Core Journals, SUDOC, ULRICHS. Esta revista es de acceso libre mediante licencia Creative Commons 4.0 CC by. Política de archivado: etiqueta verde SHERPA-ROMEO. 


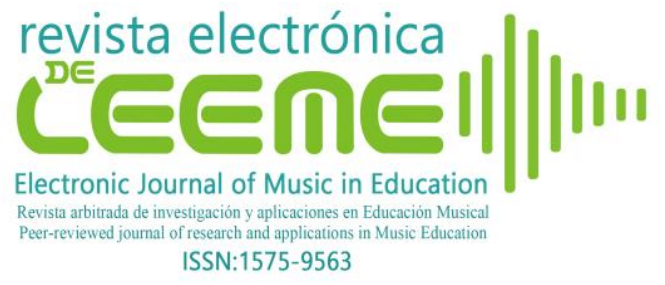

Los datos y situaciones expuestas remiten a la última categoría de análisis formulada para los resultados de la investigación, es decir, a la identidad de las alumnas que protagonizan este trabajo, y permiten inferir que la mayoría revela orientaciones positivas hacia la discapacidad, es decir, que son personas para las que la diversidad funcional es solo un rasgo más de su amplio abanico de identidades, pero no el principal. Así, aunque es evidente que existen varios componentes que influyen en la (auto)percepción de esta — como el grado en el que limite las actividades de la vida diaria o cómo actúe el entorno familiar y socio-educativo (Palacios, 2008)—, en el caso de las personas entrevistadas parece claro que la identidad musical y cultural que imprime el flamenco es mayor que la derivada de la capacidad. Buena muestra de ello es Gana, quien, en palabras de Gauri, su madre, "siente una gran alegría por y para el baile y el flamenco", hasta el punto de que

\footnotetext{
"cuando hay que castigarla severamente por algo que no ha hecho bien, decirle que no va a ir a flamenco es una de las pocas cosas que no la dejan impasible: quitarle las chucherías o incluso dejarla sin comer no le afecta, para ella [son cosas que] tienen solución, pero dejarla sin bailar, no" (Gauri, entrevista, 4 de febrero de 2020).
}

También en el de Denali, quien no pertenece a ninguna asociación de sordos y quien critica que haya "muchos sordos de mente", porque se encierran en su situación específica: ella tiene muy claro que "el mundo es de los oyentes y [que es ella] la que t[iene] que adaptar[s]e" (Denali, entrevista, 21 de enero de 2020). Un ejemplo aún más evidente es el de la citada Nahali, maestra funcionaria por turno libre, especialista en Educación Infantil, a quien su pérdida de audición severa no le impide la absoluta normalidad de comunicación pese a no emplear audífonos. La razón es sencilla: su opción ha sido siempre la de adaptarse y superar la dificultad que supone su diversidad funcional, también en el entorno del baile flamenco.

No obstante, se han localizado igualmente casos de personas con una identidad negativa, que resulta en una mayor dificultad de las profesoras que tienen una actitud empática para desarrollar su trabajo. Es lo que considera Janet respecto a Jenya, cuya familia no ha manifestado ninguna información acerca de su discapacidad — intelectual—, a pesar de que lleva varios años en su escuela, complicando cualquier tipo de adaptación.

\section{Discusión y conclusiones}

A lo largo de la investigación, ha podido constatarse que, en Granada a día de la fecha, existen 22 escuelas de flamenco de diversa índole, de las que 13 respondieron positivamente para participar en este estudio. Puede decirse, entonces, que existe un elevado número de EE.FF. en relación con la población censada — 1/10.554 habitantes_, sobre todo si se compara con la de centros públicos dispuestos para las diferentes etapas de enseñanza obligatoria 1/7.036 habitantes en el caso de los CEIP, 1/11.610 habitantes en el caso de los IES (Junta de Andalucía, 2019)—. Parece claro, además, que los centros bajo escrutinio, corroborando lo

@Carmen Ramírez-Hurtado y Consuelo Pérez-Colodrero. The content of this article is the sole responsibility of the authors. The Revista Electrónica de LEEME and Universitat de València are not liable for any legal actions that may arise involving the article's content. Revista Electrónica de LEEME - Lista Electrónica Europea de Música en la Educación-. http://ojs.uv.es/index/php/LEEME/index ISSN: 1575-9563. Editores: Universidad de Valencia y Jesús Tejada. Visibilidad de esta revista: SCOPUS, Emerging Sources Citation Index (Clarivate), EBSCO, CINDOC (CSIC), Citefactor, COPAC, Dialnet, DICE (CSIC), DOAJ, e-revistas (CSIC), EBSCO Premier, ERIH+, Gale Cengage Learning, IN-RECS, IRESIE, LATINDEX, MIAR, OCLC Worldcat, RESH, REDIB, RILM Core Journals, SUDOC, ULRICHS. Esta revista es de acceso libre mediante licencia Creative Commons 4.0 CC by. Política de archivado: etiqueta verde SHERPA-ROMEO. 
apuntado por De las Heras-Fernández y García-Gil (2019), llegan a amplias capas de la sociedad local y, como consecuencia, actúan como auténticos divulgadores de la cultura flamenca en la ciudad. Resulta llamativo, asimismo, que estos centros generalmente ofrecen el baile antes que el toque y el cante a sus alumnas. Este aspecto puede relacionarse con la demanda que esta disciplina tiene entre el alumnado en Granada, que a su vez concuerda con su estabilidad en el ámbito comercial, en el que se muestra como un espectáculo de amplia distribución en establecimientos tanto públicos como privados (Palma-Martos, Martín-Navarro, Rodríguez-Ramos y Palma-Martos, 2014).

La totalidad de las EE.FF. incluidas en este estudio cuentan o han contado con alumnado con diversidad funcional en algún momento de su trayectoria, siendo entonces mayoría los centros de Granada que trabajan con estudiantes con diferentes capacidades (13/22), según los datos que se han obtenido.

A la hora de adaptar las enseñanzas ofertadas a este tipo de alumnas, el profesorado de las EE.FF. actúa en función de su formación universitaria — Leslie y Maddie son licenciadas en Psicología - o porque han recibido el apoyo de personal cualificado en diversidad funcional como los intérpretes de lengua de signos que han colaborado en algunas clases de la escuela $\mathrm{D}$ - . Estos últimos centros, que han podido aplicar adaptaciones técnicas en todos o algunos casos, se han etiquetado en este trabajo como segregados o integrados. En las escuelas preinclusivas, que constitiuyen la mayoría de los casos identificados, se aplica en cambio lo que se ha denominado adaptación empático-intuitiva. Esta, basada en la decisión de las docentes, se encuentra en consonancia con el estilo comando de enseñanza, es decir, con la fórmula con la que tradicionalmente se ha enseñado y aprendido el flamenco (De las Heras-Fernández, Espada y Cuéllar-Moreno, 2019). Dicho estilo de enseñanza supone un aprendizaje procedimental, de ejemplificación continua, en el que resulta fácil, además, identificar las dificultades de aprendizaje de las estudiantes y encauzarlas hacia su mejora inmediata. Este punto de partida técnico-metodológico favorece la empatía, que resulta crucial para la inclusión efectiva.

Desde el punto de vista fenomenológico, la empatía es la experiencia de la conciencia ajena (Stein, 2004), lo que supone que el cuerpo - y su expresión creativa- es un fenómeno bajo el que se encuentra la persona con toda su dignidad y sus capacidades. Así, la experiencia corporal en el flamenco supone una proximidad auténtica que no es solo afectiva y que implica un vínculo primordial, consciente y construido. A partir de estas premisas, se hace fácil establecer, por parte de la discente, el cuidado, el diálogo, la proximidad y la apertura hacia sus alumnas. Dado que la capacidad para la empatía puede relacionarse con la historia biográfica de cada persona, las bailaoras-profesoras entrevistadas para este trabajo se redimensionan como personas potencialmente empáticas por cuanto que la música, en sí misma y, muy particularmente, en su práctica en la dimensión corporal, propicia esta empatía, como ampliamente ha estudiado Laurence $(2008,2011)$. Como resultado, su práctica docente se ve

@Carmen Ramírez-Hurtado y Consuelo Pérez-Colodrero. The content of this article is the sole responsibility of the authors. The Revista Electrónica de LEEME and Universitat de València are not liable for any legal actions that may arise involving the article's content. Revista Electrónica de LEEME - Lista Electrónica Europea de Música en la Educación-. http://ojs.uv.es/index/php/LEEME/index ISSN: 1575-9563. Editores: Universidad de Valencia y Jesús Tejada. Visibilidad de esta revista: SCOPUS, Emerging Sources Citation Index (Clarivate), EBSCO, CINDOC (CSIC), Citefactor, COPAC, Dialnet, DICE (CSIC), DOAJ, e-revistas (CSIC), EBSCO Premier, ERIH+, Gale Cengage Learning, IN-RECS, IRESIE, LATINDEX, MIAR, OCLC Worldcat, RESH, REDIB, RILM Core Journals, SUDOC, ULRICHS. Esta revista es de acceso libre mediante licencia Creative Commons 4.0 CC by. Política de archivado: etiqueta verde SHERPA-ROMEO. 
imbuida de esta cualidad, que las lleva a modificar su metodología para adaptarla a sus estudiantes funcionalmente diversas aun cuando no tengan formación específica al efecto. Así, dado que las adaptaciones que se realizan en este particular contexto derivan de la intuición y de la conexión empática de las profesoras hacia sus alumnas, pero no de la cualificación expresa que, salvo en los casos apuntados, no han recibido en su formación como bailaoras- el planteamiento de esta investigación les ha hecho reflexionar sobre su práctica docente y reconocer que sería útil que existiera una guía operativa de buenas prácticas para personas con distintas capacidades.

Las entrevistas a alumnas con diversidad funcional ilustran que la ciudad donde se realiza el estudio es pertinente para observar cómo la identidad-cultural que imprime el flamenco es más fuerte que la identidad-discapacidad en el caso de las personas involucradas en el mismo. Al tiempo, sugieren que el diseño educativo universal aplicado a los procesos de enseñanza-aprendizaje no-formales del flamenco beneficia a la generalidad de la población, pues es útil no sólo a las personas con diferentes capacidades, sino a la generalidad de la población —a quienes tienen pocas aptitudes rítmicas, están culturalmente alejadas del flamenco o, simplemente, se acercan a la senectud-, propiciando la justicia social y la sostenibilidad de la cultura (Hanesworth, Bracken y Elkington, 2019; Escribano-González y Martínez-Cano, 2013). En realidad, cualquier persona está capacitada para el flamenco, pues las barreras provienen del contexto socio-cultural antes que, de la diferencia, tal como han señalado el paradigma social y el de la diversidad funcional de la discapacidad. Así, este trabajo muestra cómo las personas con diversidad funcional pueden practicar flamenco a nivel amateur e incluso profesional. Se revela de este modo que el flamenco puede ser un arte inclusivo, desarrollándose con una perspectiva abierta a todas las capacidades.

\section{Referencias}

Ainscow, M. (2001). Desarrollo de escuelas inclusivas: ideas, propuestas y experiencias para mejorar las instituciones escolares. Madrid: Narcea.

Armstrong, D., Armstrong, A. y Spandagou. I. (2011). Inclusion: by choice or by chance? International Journal of Inclusive Education, 15(1), 29-39. doi: $10.1080 / 13603116.2010 .496192$

Arrebola, A. (2018). Granada en el arte flamenco. Granada: Diputación de Granada.

Barnartt, S. (2010). Disability as a fluid state. Bingley, UK: Emerald.

Berlanga-Fernández, M.A. (2009). El arte flamenco: un referente simbólico más de lo andaluz. En M.A. Berlanga-Fernández (Ed.), Lo andaluz popular, símbolo de lo nacional (pp.1543). Granada: Universidad de Granada.

@Carmen Ramírez-Hurtado y Consuelo Pérez-Colodrero. The content of this article is the sole responsibility of the authors. The Revista Electrónica de LEEME and Universitat de València are not liable for any legal actions that may arise involving the article's content. Revista Electrónica de LEEME - Lista Electrónica Europea de Música en la Educación-. http://ojs.uv.es/index/php/LEEME/index ISSN: 1575-9563. Editores: Universidad de Valencia y Jesús Tejada. Visibilidad de esta revista: SCOPUS, Emerging Sources Citation Index (Clarivate), EBSCO, CINDOC (CSIC), Citefactor, COPAC, Dialnet, DICE (CSIC), DOAJ, e-revistas (CSIC), EBSCO Premier, ERIH+, Gale Cengage Learning, IN-RECS, IRESIE, LATINDEX, MIAR, OCLC Worldcat, RESH, REDIB, RILM Core Journals, SUDOC, ULRICHS. Esta revista es de acceso libre mediante licencia Creative Commons 4.0 CC by. Política de archivado: etiqueta verde SHERPA-ROMEO. 
Brabazon, T. (2015). Enabling University: Impairment, (Dis)ability and Social Justice in Higher Education. New York: Springer.

Calderón-Almendros, I. y Calderón-Almendros, R. (2016). 'I open the coffin and here I am': disability as oppression and education as liberation in the construction of personal identity. Disability \& Society, 31(1), 100-115. doi: 10.1080/09687599.2015.1133400

Casas-Mas, A., Pozo, J.I. y Montero, I. (2015). The influence of musical learning cultures on the construction of teaching-learning conceptions. British Journal of Music Education, 31(3), 319-342. doi: 10.5429/2079-3871(2015)v5i1.5es

Charalampos, S., Silva, C.F. y Kudlacek, M. (2015). When sitting becomes a sport: life stories in sitting voeiball. European Journal of Adapted Physical Activity, 8, 30-44. doi: 10.5507/euj.2015.003

Cotán-Fernández, A. (2015). Enseñanza Superior y educación inclusiva: múltiples miradas desde las historias de vida de estudiantes con discapacidad [Tesis Doctoral, Universidad de Sevilla].

Davis, L.J. (Ed.) (2017). The Disabilities Studies Reader. New York: Routledge.

Darling, R.B. (2014). Disability and identity: Negotiating self in a changing society. Boulder, CO: Lynne Rienner.

De las Heras-Fernández, R. y García-Gil, D. (2019). Estudio de los procesos de enseñanzaaprendizaje del flamenco a través de entrevistas. La visión de las mujeres. Revista electrónica de LEEME, 43, 50-73. doi: 10.7203/LEEME.43.13587

De las Heras-Fernández, R., Espada, M.R.I.A. y Cuellar-Moreno, M. (2019). Percepciones de los/as estudiantes en los estilos de enseñanza comando y resolución de problemas en el aprendizaje del baile flamenco. Prisma Social, 25, 84-102. Recuperado de: https://revistaprismasocial.es/article/view/2601

De Sancha-Navarro, J.M., Martos, L.P. y Oliver-Alfonso, M.D. (2019). Explanatory factors of university student participation in flamenco. Economics and Sociology, 12(4), 130-148. doi: 10.14254/2071-789X.2019/12-4/8

Escribano-González, A. y Martínez-Cano, A. (2013). Inclusión educativa y profesorado inclusivo: aprender juntos para aprender a vivir juntos. Madrid: Narcea.

Ferreira, M.A.V. (2008). Una aproximación sociológica a la discapacidad desde el modelo social: apuntes caracteriológicos. Revista Española de Investigaciones Sociológicas,

@Carmen Ramírez-Hurtado y Consuelo Pérez-Colodrero. The content of this article is the sole responsibility of the authors. The Revista Electrónica de LEEME and Universitat de València are not liable for any legal actions that may arise involving the article's content. Revista Electrónica de LEEME - Lista Electrónica Europea de Música en la Educación-. http://ojs.uv.es/index/php/LEEME/index ISSN: 1575-9563. Editores: Universidad de Valencia y Jesús Tejada. Visibilidad de esta revista: SCOPUS, Emerging Sources Citation Index (Clarivate), EBSCO, CINDOC (CSIC), Citefactor, COPAC, Dialnet, DICE (CSIC), DOAJ, e-revistas (CSIC), EBSCO Premier, ERIH+, Gale Cengage Learning, IN-RECS, IRESIE, LATINDEX, MIAR, OCLC Worldcat, RESH, REDIB, RILM Core Journals, SUDOC, ULRICHS. Esta revista es de acceso libre mediante licencia Creative Commons 4.0 CC by. Política de archivado: etiqueta verde SHERPA-ROMEO. 
ISSN:1575-9563

124,

141-174.

Recuperado

de: http://www.reis.cis.es/REIS/PDF/REIS_124_051222873458779.pdf

García-Gil, D. y Azcune, B.L. (2012). Flamenco y nuevas tecnologías: El aula de música como contexto para la integración del colectivo gitano. Publicaciones de la Facultad de Educación y Humanidades del Campus de Melilla, 42, 121-132. Recuperado de: https://revistaseug.ugr.es/index.php/publicaciones/article/view/2184

Gerrity, K.W., Hourigan, R.M., y Horton, P.W. (2013). Conditions that facilitate music learning among students with special needs: A mixed-methods inquiry. Journal of Research in Music Education, 61(2), 144-159. doi: 10.1177/0022429413485428

Giménez-Miranda, J.M. (2010). Albéniz, Falla, Granada y el Flamenco. Papeles del Festival de Música Española de Cádiz, 5, 81-97. Recuperado de: http://www.centrodedocumentacionmusicaldeandalucia.es/opencms/documentac ion/revistas/articulos-pfmec/albeniz-falla-granada-y-el-flamenco.html

Hanesworth, P., Bracken, S. y Elkington, S. (2019). A typology for a social justice approach to assessment: learning from universal design and culturally sustaining pedagogy. Teaching in Higher Education, 24(1), 98-114. doi: 10.1080/13562517.2018.1465405

Hoinville, G. y Jowell, R. (1978). Survey Research Practice. London, UK: Heinemann.

Iyanga, A. (2017). La educación inclusiva perspectiva histórica y situación actual. Madrid: Tirant.

Jefatura del Estado (2007). Ley Orgánica 2/2007, de 19 de marzo, de reforma del Estatuto de Autonomía para Andalucía. BOE (20/03/2007), núm.68, referencia 5825, pp.1187111909.

Johnstone, C.J. (2004). Disability and identity: Personal constructions and formalized supports. Disability Studies Quarterly, 24(4). doi: 10.18061/dsq.v24i4.880

Jorgensen, E.R. (2009). On thick description and narrative inquiry in music education. Research Studies in Music Education, 31(1), 69-81. doi: 10.1177/1321103X09103632

Junta de Andalucía, Localizador de Centros [curso 2019/2020]. Recuperado de https://www.juntadeandalucia.es/educacion/vscripts/centros/Escolarizacion2019/index.a $\underline{\mathrm{sp}}$

Kallio-Tavin, M. (2020). Disability studies as a site of knowledge in art education. International Journal of Education Through Art, 16(1), 3-11. doi: 10.1386/eta_00013_2

@Carmen Ramírez-Hurtado y Consuelo Pérez-Colodrero. The content of this article is the sole responsibility of the authors. The Revista Electrónica de LEEME and Universitat de València are not liable for any legal actions that may arise involving the article's content. Revista Electrónica de LEEME - Lista Electrónica Europea de Música en la Educación-. http://ojs.uv.es/index/php/LEEME/index ISSN: 1575-9563. Editores: Universidad de Valencia y Jesús Tejada. Visibilidad de esta revista: SCOPUS, Emerging Sources Citation Index (Clarivate), EBSCO, CINDOC (CSIC), Citefactor, COPAC, Dialnet, DICE (CSIC), DOAJ, e-revistas (CSIC), EBSCO Premier, ERIH+, Gale Cengage Learning, IN-RECS, IRESIE, LATINDEX, MIAR, OCLC Worldcat, RESH, REDIB, RILM Core Journals, SUDOC, ULRICHS. Esta revista es de acceso libre mediante licencia Creative Commons 4.0 CC by. Política de archivado: etiqueta verde SHERPA-ROMEO. 
Kattari, S.K., Olzman, M. y Hanna, M.D. (2018). "You Look Fine!": Ableist Experiences by People With Invisible Disabilities. Affilia: Journal of Women and Social Work, 33(4), 477-492. doi: 10.1177/0886109918778073

Laurence, F. (2008). Music and enmpathy. In O. Urbain (Ed.), Music and conflict transformation (pp.13-26). New York: I.B. Tauris.

Laurence, F. (2011). Musicking and empathic connections. In O. Urbain y F. Laurence (Eds.), Music and solidarity: Questions of Universality, Consciousness, and Connection (pp. 171-185-185). London, UK: Tauris.

Levy, S., Robb, A.J. y Jindal-Snape, D. (2017). Disability, personalisation and community arts: exploring the spatial dynamics of children with disabilities participating in inclusive music classes. Disability \& Society, 32(2), 254-268. doi: 10.1080/09687599.2016.1276433

López-López, J. (2015). Más allá de la piel y la máscara: turismo, autenticidad y prácticas expositivas en el Sacromonte. Disparidades, 70(2), 527-546. doi: 10.3989/rdtp.2015.02.011

Lorente-Rivas, M. (1999). Estructura, sistema y metaestructura del flamenco en Granada [Tesis Doctoral, Universidad de Granada].

Marchesi, A. et al. (2002). Desarrollo psicológico y educación. Madrid: Alianza.

Ministerio de Educación y Ciencia (1985). Real Decreto 334/1985, de 6 de marzo, de ordenación de la Educación Especial. BOE (16/03/1985), núm.65, referencia 4305, pp.6917-6920.

Molina-Fajardo, E. (1974). El flamenco en Granada: teoría de sus orígenes e historia. Granada: Miguel Sánchez.

Navas-Fernández, E. y López-Martínez, O. (2018). El flamenco como herramienta educativa para el desarrollo de las competencias básicas en la Educación Secundaria Obligatoria: Experiencias transversales en la Escuela de Enseñanza Secundaria y Artística. En A.M. Díaz-Olaya (Ed.), Danza, Investigación y Educación: experiencias interdisciplinares con música, literatura y teatro (pp. 205-220). Granada: Libargo.

Oakland, J., MacDonald, R. y Flowers, P. (2014). Musical disembodiment: A phenomenological case study investigating the experiences of operatic career disruption due to physical incapacity. Research Studies in Music Education, 36(1), 39-55. doi:10.1177/1321103X14521355

@Carmen Ramírez-Hurtado y Consuelo Pérez-Colodrero. The content of this article is the sole responsibility of the authors. The Revista Electrónica de LEEME and Universitat de València are not liable for any legal actions that may arise involving the article's content. Revista Electrónica de LEEME - Lista Electrónica Europea de Música en la Educación-. http://ojs.uv.es/index/php/LEEME/index ISSN: 1575-9563. Editores: Universidad de Valencia y Jesús Tejada. Visibilidad de esta revista: SCOPUS, Emerging Sources Citation Index (Clarivate), EBSCO, CINDOC (CSIC), Citefactor, COPAC, Dialnet, DICE (CSIC), DOAJ, e-revistas (CSIC), EBSCO Premier, ERIH+, Gale Cengage Learning, IN-RECS, IRESIE, LATINDEX, MIAR, OCLC Worldcat, RESH, REDIB, RILM Core Journals, SUDOC, ULRICHS. Esta revista es de acceso libre mediante licencia Creative Commons 4.0 CC by. Política de archivado: etiqueta verde SHERPA-ROMEO. 
Olsson, I., Sand, M.L. y Stenberg, G. (2019). Teachers' perception of inclusion in elementary school: The importance of imitation doi: 10.1080/08856257.2019.1709704

Organización Mundial de la Salud (2001). Clasificación Internacional del Funcionamiento, de la Discapacidad y de la Salud: CIF. Madrid: Ministerio de Trabajo y Asuntos Sociales.

Padial-Ruz, R., Ibáñez-Granados, D., Hervás, M.F. y Ubago-Jiménez, J.L. (2019). Proyecto de baile flamenco: Desarrollo motriz y emocional en educación infantil. Retos, 35, 396401. https://recyt.fecyt.es/index.php/retos/article/view/63292/41745

Palacios, A. (2008). El modelo social de la discapacidad: orígenes, caracterización y plasmación en la Convención Internacional sobre los Derechos de las Personas con Discapacidad. Madrid: Cinca.

Palacios, A. y J. Romañach (2006). El modelo de la diversidad: La Bioética y los Derechos Humanos como herramientas para alcanzar la plena dignidad en la diversidad funcional. Valencia: Diversitas-AlES.

Palma-Martos, L., Martín-Navarro, J.L., Rodríguez-Ramos, A. y Palma-Martos, M.L. (2014). El flamenco como bien cultural: Una caracterización de la oferta de espectáculos en vivo y su evolución en la ciudad de Sevilla (Spain), 2006-2013. Anales de economía aplicada, 28 , 747-766. Recuperado de: https://dialnet.unirioja.es/servlet/articulo?codigo $=5057635$

Pérez-Serrano, G. (2002). Investigación cualitativa: Retos e interrogantes. Madrid: La Muralla.

Rodríguez-Quiles, J.A. (2006). Flamenco, pedagogía de la diferencia y formación inicial del profesorado de música. Revista electrónica de LEEME, 18, 1-19. Recuperado de: https://ojs.uv.es/index.php/LEEME/article/view/9762/9196

Romero, M.N., Chinchilla-Minguet, J.L. y Castillo-Rodríguez, A. (2020). Estudio de los procesos cognitivos en bailarines semi-profesionales. Retos, 37, 493-497. Recuperado de: https://recyt.fecyt.es/index.php/retos/article/view/70936

Ruiz, J. (2003). Metodología de la investigación cualitativa. Bilbao: Universidad de Deusto.

Sen, A. (1999). Reason before identity. Oxford, UK: Oxford University Press.

Solvang, P.K. (2018). Between art therapy and disability aesthetics: a sociological approach for understanding the intersection between art practice and disability discourse. Disability \& Society, 33(2), 238-253. doi: 10.1080/09687599.2017.1392929

@Carmen Ramírez-Hurtado y Consuelo Pérez-Colodrero. The content of this article is the sole responsibility of the authors. The Revista Electrónica de LEEME and Universitat de València are not liable for any legal actions that may arise involving the article's content. Revista Electrónica de LEEME - Lista Electrónica Europea de Música en la Educación-. http://ojs.uv.es/index/php/LEEME/index ISSN: 1575-9563. Editores: Universidad de Valencia y Jesús Tejada. Visibilidad de esta revista: SCOPUS, Emerging Sources Citation Index (Clarivate), EBSCO, CINDOC (CSIC), Citefactor, COPAC, Dialnet, DICE (CSIC), DOAJ, e-revistas (CSIC), EBSCO Premier, ERIH+, Gale Cengage Learning, IN-RECS, IRESIE, LATINDEX, MIAR, OCLC Worldcat, RESH, REDIB, RILM Core Journals, SUDOC, ULRICHS. Esta revista es de acceso libre mediante licencia Creative Commons 4.0 CC by. Política de archivado: etiqueta verde SHERPA-ROMEO. 
Staab, K.W. y Dvorak, A.L. (2019). Perception of music therapy by direct care staff of older adults with intellectual disabilities. Music Therapy Perspectives, 37(1), 45-54. doi:10.1093/mtp/miy021

Stein, E. (2004). Sobre el problema de la empatía. Madrid: Trotta.

Steingress, G. (2005). Sociología del cante flamenco. Sevilla: Signatura.

Toboso-Martín M. (2018). Diversidad funcional: hacia un nuevo paradigma en los estudios y en las políticas sobre discapacidad. Política y Sociedad, 55(3), 783-804. doi: 10.5209/POSO.56717

Torres, C.P., Ortega-Ruz, R. e Hidalgo, A.J.R. (2017). Integración de la especialidad de flamenco en el grado superior de Música. RECIEM, 14, 351-368. doi: 10.5209/RECIEM.49527

UNESCO ([2010]). El flamenco. Recuperado de: https://ich.unesco.org/es/RL/el-flamenco$\underline{00363}$

UNESCO (2017). Guía para asegurar la inclusión y equidad en educación. París: UNESCO.

Zitomer, M.R. y Reid, G. (2011). To be or not to be-able to dance: Integrated dance and children's perceptions of dance ability and disability. Research in Dance Education, 12(2), 137-156. doi:10.1080/14647893.2011.575224

@Carmen Ramírez-Hurtado y Consuelo Pérez-Colodrero. The content of this article is the sole responsibility of the authors. The Revista Electrónica de LEEME and Universitat de València are not liable for any legal actions that may arise involving the article's content. Revista Electrónica de LEEME - Lista Electrónica Europea de Música en la Educación-. http://ojs.uv.es/index/php/LEEME/index ISSN: 1575-9563. Editores: Universidad de Valencia y Jesús Tejada. Visibilidad de esta revista: SCOPUS, Emerging Sources Citation Index (Clarivate), EBSCO, CINDOC (CSIC), Citefactor, COPAC, Dialnet, DICE (CSIC), DOAJ, e-revistas (CSIC), EBSCO Premier, ERIH+, Gale Cengage Learning, IN-RECS, IRESIE, LATINDEX, MIAR, OCLC Worldcat, RESH, REDIB, RILM Core Journals, SUDOC, ULRICHS. Esta revista es de acceso libre mediante licencia Creative Commons 4.0 CC by. Política de archivado: etiqueta verde SHERPA-ROMEO. 
Anexo 1

Tabla 3. Modelo de entrevista

\begin{tabular}{|c|c|c|c|c|}
\hline CATEGORÍAS & ÁMBITOS & DIMENSIONES & PREGUNTAS & N. ${ }^{\circ}$ \\
\hline \multirow[t]{16}{*}{ DIRECTORA } & Personal & Edad & ¿Cuántos años tiene? & 1 \\
\hline & Profesional & Formación & ¿Cuál es su formación exacta en el ámbito de la danza? & 2 \\
\hline & & & ¿Ha cursado formación superior (universidad) además de la propiamente vinculada a la danza? & 3 \\
\hline & & Experiencia & ¿Cuál es su experiencia profesional como bailaora y/o bailarina? & 4 \\
\hline & Escuela & Características & ¿Cuándo y por qué decidió fundar una escuela de flamenco? & 5 \\
\hline & & & Aproximadamente, ¿qué número de estudiantes acude [a su centro]? & 6 \\
\hline & & $\begin{array}{l}\text { Herramientas } \\
\text { docentes }\end{array}$ & ¿Cuál es su formación, como docente, en relación con la diversidad funcional? & 7 \\
\hline & & Discapacidad & A lo largo de estos años, ¿ha tenido o tiene alguna alumna con discapacidad en tu escuela? & 8 \\
\hline & & & $\begin{array}{c}\text { ¿Con qué tipo de discapacidad? Piense también en discapacidades ocultas, como la fibromialgia o la discapacidad } \\
\text { psíquica (depresión) }\end{array}$ & 9 \\
\hline & & & $\begin{array}{l}\text { ¿Qué circunstancias recuerda de este tipo de alumnas (edad, tiempo que estuvieron en clase, limitaciones que suponía } \\
\text { su diversidad funcional, relación con sus compañeros y compañeras)? }\end{array}$ & 10 \\
\hline & & & ¿Podría comentarnos algún ejemplo que recuerde especialmente? & 11 \\
\hline & & & $\begin{array}{c}\text { En general, las familias del estudiantado con diversidad funcional, ¿informan de sus capacidades particulares y } \\
\text { necesidades educativas? }\end{array}$ & 12 \\
\hline & & & ¿Cómo se desarrolla su relación con las familias en términos de información y comunicación? & 13 \\
\hline & & Adaptación & $\begin{array}{l}\text { Estas personas, ¿acudieron a una clase específica, es decir, fuera del grupo habitual, o se integraron en el grupo } \\
\text { general? }\end{array}$ & 14 \\
\hline & & & ¿Cómo adaptó la enseñanza para que estas personas pudieran participar de y en la clase? & 15 \\
\hline & & & ¿Participaron en el festival o función con los demás? & 16 \\
\hline \multirow[t]{5}{*}{ ALUMNA } & Personal & Familia & ¿Cuántas personas constituyen la unidad familiar? & 17 \\
\hline & & & Además de (nombre de la alumna), ¿alguien más en casa tiene capacidades diversas? & 18 \\
\hline & & Dedicación padres & ¿Cuál es la dedicación profesional de los padres de (nombre de la alumna)? & 19 \\
\hline & Discapacidad & Diagnóstico & ¿Cuál es la diversidad funcional de su hijo/a? ¿Está diagnosticada? & 20 \\
\hline & & Educación no-formal & ¿Qué otras actividades de esta naturaleza (baile, música, deporte) practica su hija/o? & 21 \\
\hline
\end{tabular}




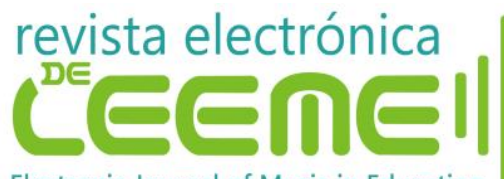

Electronic Journal of Music in Education

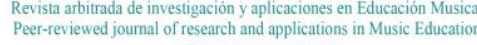

SSN $1575-9563$

e informal

Activismo

¿Pertenecen a algún tipo de asociación relacionada con la discapacidad?

Cuál es la actitud que toma su hija/o respecto a su discapacidad?

Flamenco

Inicios

¿Reciben algún tipo de orientación profesional además de la proporcionada por el centro educativo?

¿Cuántos años lleva su hijo/a bailando flamenco?

Beneficios

¿Cuáles fueron las razones para que escogieran el baile flamenco para complementar la educación de vuestra/o hija/o?

¿Cuál es la relación de su hija/o con el flamenco?

A su juicio, ¿qué beneficios le reporta?

Escuela

$\mathrm{Su}$ hija/o, ¿se siente integrada/o en su clase?

Fuente: Elaboración propia 